\title{
Proposing the lymphatic target volume for elective radiation therapy for pancreatic cancer: a pooled analysis of clinical evidence
}

\author{
Wenjie Sun $^{1 \dagger}$, Cheng N Leong ${ }^{2 \dagger}$, Zhen Zhang ${ }^{1 *}$, Jiade J Lu ${ }^{1,2}$
}

\begin{abstract}
Background: Radiation therapy is an important cancer treatment modality in both adjuvant and definitive setting, however, the use of radiation therapy for elective treatment of regional lymph nodes is controversial for pancreatic cancer. No consensus on proper selection and delineation of subclinical lymph nodal areas in adjuvant or definitive radiation therapy has been suggested either conclusively or proposed for further investigation. This analysis aims to study the pattern of lymph node metastasis through a pooled analysis of published results after radical tumor and lymph nodal resection with histological study in pancreatic cancer.

Methods: Literature search using electronic databases including MEDLINE, EMBASE, and CANCERLIT from January 1970 to June 2009 was performed, supplemented by review of references. Eighteen original researches and a total of 5954 pancreatic cancer patients underwent radical surgical resection were included in this analysis. The probability of metastasis in regional lymph nodal stations (using Japan Pancreas Society [JPS] Classification) was calculated and analyzed based on the location and other characteristics of the primary disease.
\end{abstract}

Results: Commonly involved nodal regions in patients with pancreatic head tumor include lymph nodes around the common hepatic artery (Group 8, 9.79\%), posterior pancreaticoduodenal lymph nodes (Group 13, 32.31\%), lymph nodes around the superior mesenteric artery (Group 14, 15.85\%), paraaortic lymph nodes (Group 16, 10.92\%), and anterior pancreaticoduodenal lymph nodes (Group 17, 19.78\%); The probability of metastasis in other lymph nodal regions were $<9 \%$.

Commonly involved nodal regions in patients with pancreatic body/tail tumor include lymph nodes around the common hepatic artery (Group 8, 15.07\%), lymph nodes around the celiac trunk (Group 9, 9.59\%), lymph nodes along the splenic artery (Group 11, 35.62\%), lymph nodes around the superior mesenteric artery (Group 14, 9.59\%), paraaortic lymph nodes (Group 16, 16.44\%), and inferior body lymph nodes (Group 18, 24.66\%). The probability of metastasis in other lymph nodal regions were $<9 \%$.

Conclusions: Pancreatic cancer has a high propensity of regional lymphatic metastases; however, clear patterns including the site and probability of metastasis can be identified and used as a guide of treatment in patients with resectable pancreatic cancer. Further clinical investigation is needed to study the efficacy of elective treatment to CTV defined based on these patterns using high-dose conformal or intensity-modulated radiation therapy.

\footnotetext{
* Correspondence: zhenzhang6@gmail.com

† Contributed equally

'Department of Radiation Oncology, Fudan University Shanghai Cancer

Center Department of Oncology, Shanghai Medical College, Fudan

University, Shanghai 200032, China
} 


\section{Introduction}

Pancreatic cancer is a highly malignant neoplasm of GI system, and radical surgery is its only curative treatment option [1]. Unfortunately, the probability of locoregional recurrence approaches $80 \%$ after complete resection, and long-term survival is less than $25 \%$ even for patients treated for early stage disease [2-4]. Adjuvant treatment is an integral part of definitive treatment of resectable pancreatic carcinoma; however, the optimal therapeutic modalities in adjuvant setting remain a focus of debate.

Radiation therapy is commonly used in adjuvant treatment for pancreatic cancer after radical surgery in the United States. The effect of radiation with concurrent 5 -FU based chemotherapy has been suggested in a number of randomized clinical trials [5-7]. In addition, concurrent chemoradiation therapy has been the mainstay treatment for nonmetastatic and inoperable pancreatic cancer $[8,9]$.

Radiation fields utilized in these trials encompassed not only subclinical nodal regions but also adjacent normal tissues. Despite such generous coverage, however, locoregional control remains a major mode of recurrence. The underlying reason for such suboptimal outcome is probably due to, at least in part, insufficient radiation dose (i.e., 45-50 Gy in conventional fractionation) to the surgical bed and draining lymph node regions limited by the organs at risk (OARs) adjacent to the pancreas and lymph nodal regions such as liver, small intestine, stomach, spinal cord, and kidneys.

The prevailing utilization of intensity-modulated radiation therapy (IMRT) in cancer treatment including upper GI malignancies enabled dose differentiation between target volumes and adjacent normal tissues and organs thereby improved therapeutic ratio. Results from recently published dosimetry studies have suggested the advantage of IMRT in the treatment of tumors of upper abdomen including pancreatic, gastric, and billiary cancers as compared to 3-dimentional conformal radiation therapy (3D-CRT) [10-13]. Proper defining of high-risk regions especially the lymph nodal regions (i.e., CTV-N) forms an imperative basis for dose escalation using IMRT. However, selection and delineation of nodal regions in both adjuvant IMRT after pancreaticoduodenectomy and in definitive setting have never been addressed.

The aim of this analysis is to address the selection of high-risk subclinical lymph nodal regions in conformal radiation therapy for resectable pancreatic cancer, by reviewing and summarizing the probability of lymph node metastases in resectable pancreatic cancer patients treated with radical surgery with lymph node dissection and pathological investigation of the resected regional nodes.

\section{Methods}

An exhaustive search and review of original articles analyzing lymph nodal positivity rate of pancreatic cancer was performed by searching MEDLINE, EMBASE, and CANCERLIT from January 1970 to June 2009. The search strategy used the following key words in various combinations: "pancreatic cancer", "pancreatic carcinoma", "lymph node", and "surgery". Based on the titles of the articles, studies not describing the pattern of lymph nodal metastasis were excluded, and the entire article of those retained and published in English were read and screened. Studies were eligible if lymph node positivity rates in pancreatic cancer were reported. We also supplemented correlative articles by reading the references of reviews.

All lymph nodes were classified according to the General Rules for Cancer of the Pancreas published by the Japan Pancreas Society (JPS) (Figure 1) [14]. Articles in which dissected lymph nodes could not be classified according to the rule of JPS were excluded. There was no restriction criterion on the number of patients enrolled in the study.

The rate of disease involvement of all lymph nodal regions (according to JPS Classification) was the primary outcome. Relationship between lymph nodal metastasis and tumor characteristics ( $\mathrm{T}$ classification, lymphatic vessel invasion, tumor location, tumor size and tumor differentiation) was also evaluated.

The accuracy of data from individual publication including the conversion to JPS lymph node classification was examined by two participants of this analysis. Pooled analyses of the rates of metastasis to lymph nodal regions were calculated and reported. Statistical correlation between metastasis to lymph node areas and tumor characteristics was performed using Fisher's exact test.

\section{Results}

\section{Characteristics of Included Studies}

The initial search resulted in 392 citations. The title and abstract of each retrieved publication were reviewed to confirm that the article reported on the incidence of lymph nodal positivity in patients with pancreatic cancer. In the event that this approach was not informative, the full article was retrieved and reviewed in detail. This process resulted in excluding 373 studies and 19 studies were selected. Of these 19 studies, one study [15] was further excluded from this analysis because we could not classify the lymph nodes of this study according to the rule of JPS (Figure 2).

In 18 eligible studies [1,16-32], 12 (66.7\%) studies described lymph nodal metastatic rates of pancreatic head cancer; cancer of body/tail of pancreas in only 2 


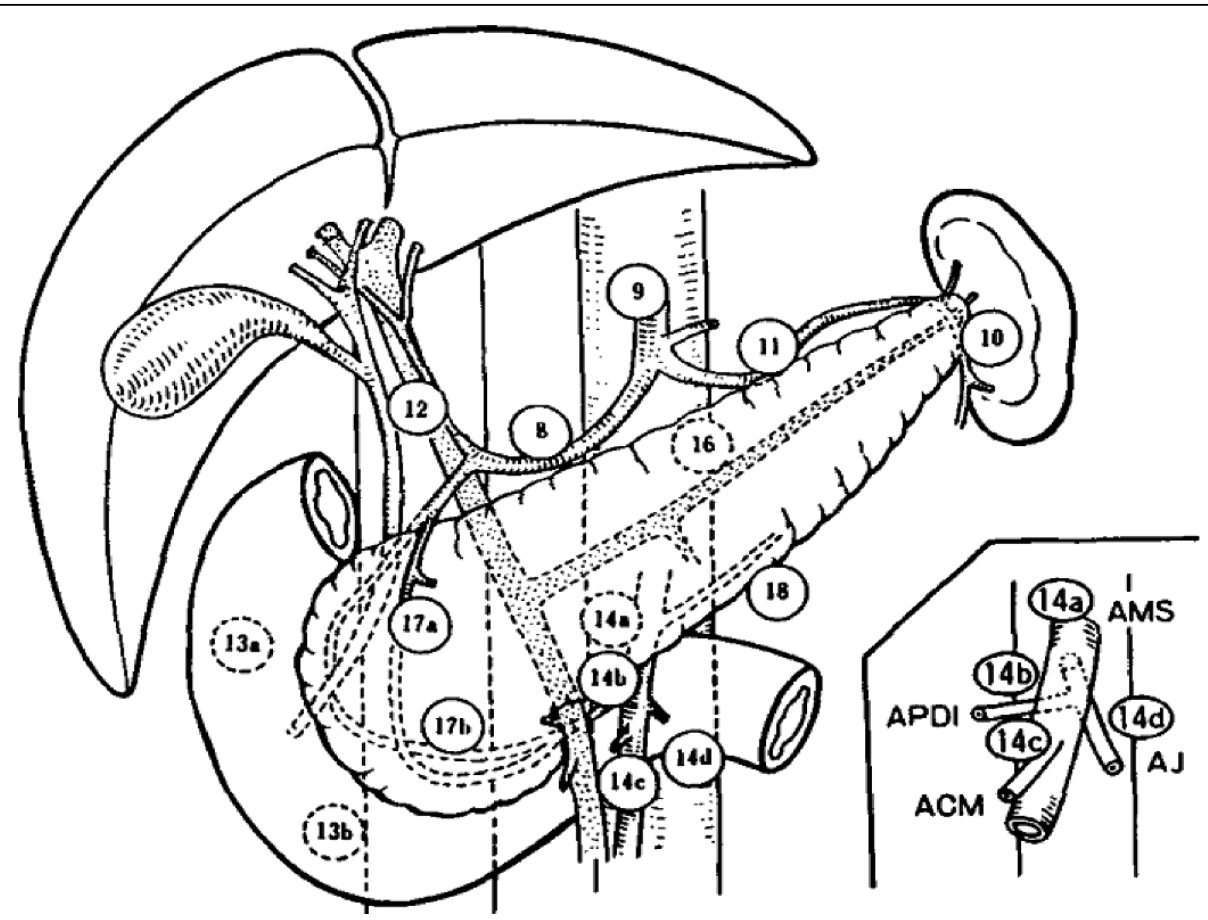

Figure 1 JPS Classification of the regional lymph nodes of the pancreas. (Adapted from Nagakawa T, Kobayashi H, Ueno K, Ohta T, Kayahara M, Mori K, Nakano T, Takeda T, Konishi I, Miyazaki I: The pattern of lymph node involvement in carcinoma of the head of the pancreas. A histologic study of the surgical findings in patients undergoing extensive nodal dissections. Int J Pancreatol. 1993,13:15-22 [19]. Used with permission from Springer Science+Business.) Insert: Subdivision of Group 14: (AMS) superior mesenteric artery; (AJ) jejunal artery; (APDI) inferior pancreaticoduodenal artery; (ACM) medial colic artery; For other abbreviations of the nodal groups refer to Table 2.

(11.1\%) studies and general pancreatic cancer (including all locations of pancreas) in $4(22.2 \%)$ studies (Table 1$)$. In analyzing the metastatic pattern of lymph nodes, we divided the data of one study about general pancreatic cancer (Study No.3) [17] into two parts (the data about pancreatic head cancer and those about pancreatic body/tail cancer), then integrated these two parts into the statistical analysis of pancreatic head and body/tail cancer respectively.

The 18 studies, which met the inclusion criteria, reported on 5954 pancreatic cancer patients who had undergone radical lymph nodes dissections (Table 1). 17 studies were prospective, and the remaining one was a statistic summary of 20 years' registry results on JPS website [1]. The median number of pancreatic cancer patients enrolled per study was 49.5 (range 8-4913 patients). In studies that provided baseline demographic information on pancreatic cancer patients, 414 were men and 242 were women [16-23]. The mean age was reported in 5 studies and ranged between 61 years and 74.8 years [17,23-25,28], and the reported median age ranged from 59 years to 65 years in 3 studies $[16,18,29]$.

Twelve of 18 (66.7\%) studies commented on the histopathologic examination of lymph nodes, which consisted of routine hematoxylin and eosin staining, with additional sections evaluated by elastica van Gieson staining in $4(33.3 \%)$ studies $[17,25,26,32]$ and by elasticMasson staining in 1 (8.3\%) study [24]. Furthermore, 16 of $18(88.9 \%)$ studies described the histopathologic type of pancreatic cancer. Of these, almost all enrolled patients' histopathologic types were ductal adenocarcinomas except for two patients. One patient's histopathological type was undifferentiated carcinoma and another was adenosquamous carcinoma.

\section{Regional lymph node metastasis pattern based on different locations of tumors}

The probability of metastasis in regional lymph nodal stations was calculated and analyzed by Japan Pancreas Society (JPS) Classification [14]. For all 5954 patients with pancreatic cancer (including head and body/tail of pancreas), commonly involved regional lymph nodal stations were lymph nodes around the common hepatic artery (Group8, 9.84\%), posterior pancreaticoduodenal lymph nodes (Group13, 32.1\%), lymph nodes around the superior mesenteric artery (Group14, 15.76\%), paraaortic lymph nodes (Group16, 11.04\%), anterior pancreaticoduodenal lymph nodes (Group17, 19.65\%). Nodal sites with a frequency of metastasis $<5 \%$ included right cardial lymph nodes (Group1, 0.39\%), left cardial lymph 


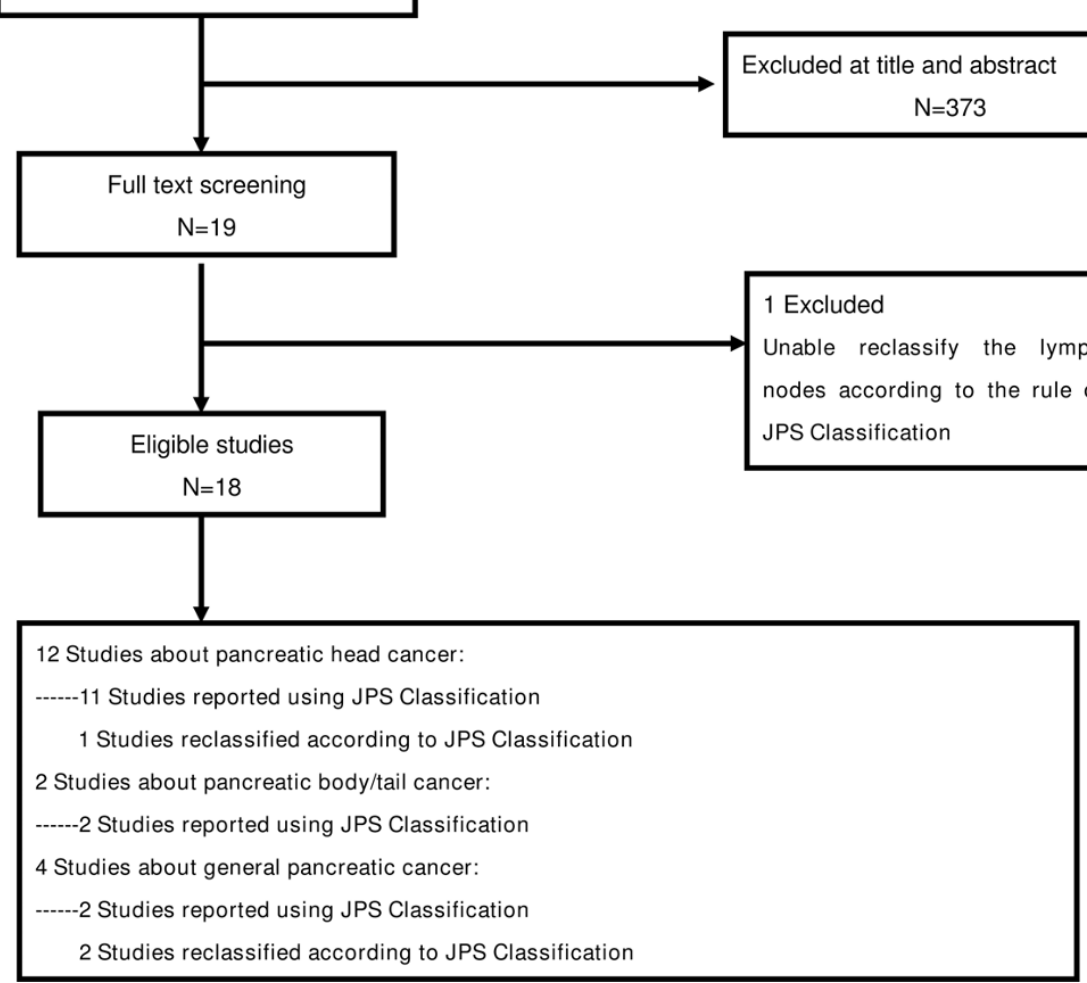

Figure 2 Flowchart of studies to final number of eligible studies.

Table 1 Classification of regional lymph nodes of the pancreas

\begin{tabular}{|c|c|c|c|c|c|}
\hline No. of Study & Studies & Year & Location of Tumors & No. of Patients & LN Positivity \\
\hline 1 & Brunner TB [16] & 1978-1997 & Head & 178 & NA \\
\hline 2 & Matsuno S [1] & $1981-2002$ & Head & 4913 & NA \\
\hline 3 & Kayahara M [17] & 1974-1996 & General* & 99 & $78 \%$ \\
\hline 4 & Sierzega M [18] & $1980-2002$ & Head & 96 & $66.70 \%$ \\
\hline $5^{\#}$ & Nagakawa T [19] & 1973-1989 & Head & 42 & $78.60 \%$ \\
\hline 6 & Nagakawa T [20] & 1973-1989 & Head & 42 & $78.60 \%$ \\
\hline 7 & Capussotti L [21] & 1988-1998 & Head & 100 & $59 \%$ \\
\hline 8 & Cubilla AL [22] & $1974-1976$ & General* & 22 & $86.40 \%$ \\
\hline 9 & Nakao A [23] & 1981-1995 & Body/tail & 30 & $46.70 \%$ \\
\hline 10 & Nagai H [24] & 1980-1983 & General* & 8 & $75 \%$ \\
\hline 11 & Kayahara M [25] & 1980-1994 & Body/tail & 20 & $80 \%$ \\
\hline 12 & Kayahara M [26] & N/A & Head & 44 & $70.50 \%$ \\
\hline 13 & Yoshida T [27] & 1995-1999 & Head & 34 & NA \\
\hline 14 & Sakai M [28] & $1981-2002$ & Head & 178 & $66 \%$ \\
\hline 15 & Gerdes B [29] & 1995-2002 & Head & 50 & $64 \%$ \\
\hline 16 & Ishikawa O [30] & 1981-1994 & Head & 81 & $73 \%$ \\
\hline 17 & Kayahara M [31] & 1973-1991 & Head & 49 & $76 \%$ \\
\hline 18 & Kocher HM [32] & $\mathrm{N} / \mathrm{A}$ & General* & 10 & $80 \%$ \\
\hline
\end{tabular}

"The patients of Study No.5 are same as those of Study No.6.

$\mathrm{N} / \mathrm{A}=$ not applicable; *"General" indicates the location of tumor in that study include either head or body/tail. 
nodes (Group2, 0.28\%), lymph nodes along the lesser curvature of the stomach (Group3, 1.2\%), lymph nodes along the greater curvature of the stomach (Group4, $1.37 \%$ ), suprapyloric lymph nodes (Group5, 1.68\%), lymph nodes around the left gastric artery (Group7, $1.73 \%$ ), lymph nodes around the celiac trunk (Group9, $3.75 \%)$, lymph nodes at the hilus of the spleen (Group10, 0.84\%), lymph nodes along the splenic artery (Group11, 1.93\%), lymph nodes along the middle colic artery (Group15, 2.7\%), inferior body lymph nodes (Group18, 3.04\%) (Table 2, Figure 3).

In 13 studies on pancreatic head cancer (including a part of data in Study No.3), metastatic rates of regional lymph nodes of 5838 patients were analyzed. Commonly involved nodal regions in patients with pancreatic head tumor included the posterior pancreaticoduodenal lymph nodes (Group 13, 32.31\%), anterior pancreaticoduodenal lymph nodes (Group 17, 19.78\%), lymph nodes around the superior mesenteric artery (Group 14, $15.85 \%$ ), paraaortic lymph nodes (Group 16, 10.92\%) and lymph nodes around the common hepatic artery (Group 8, 9.79\%). The probability of lymph nodal metastasis $<5 \%$ included right cardial lymph nodes (Group 1, 0.39\%), left cardial lymph nodes (Group 2, $0.28 \%$ ), lymph nodes along the lesser curvature of the stomach (Group 3, 1.2\%), lymph nodes along the greater curvature of the stomach (Group 4,1.38\%), suprapyloric lymph nodes (Group 5, 1.69\%), lymph nodes around the left gastric artery (Group 7, 1.74\%), lymph nodes around the celiac trunk (Group 9, 3.66\%), lymph nodes at the hilus of the spleen (Group 10, 0.78\%), lymph nodes along the splenic artery (Group 11, 1.64\%), lymph nodes along the middle colic artery (Group 15, 2.69\%) and inferior body lymph nodes (Group 18, 2.61\%) (Table 2, Figure 3).

There were 3 studies including 73 patients with cancer of body/tail of pancreas which were analyzed (including a part of data in Study No.3). Commonly involved nodal regions in patients with pancreatic body/tail tumor included lymph nodes around the common hepatic artery (Group 8, 15.07\%), lymph nodes around the celiac trunk (Group 9, 9.59\%), lymph nodes along the splenic artery (Group 11, 35.62\%), lymph nodes around the superior mesenteric artery (Group 14, 9.59\%), paraaortic lymph nodes (Group 16, 16.44\%), inferior body lymph nodes (Group 18, 24.66\%). The probability of lymph nodal metastasis $<5 \%$ included Groups 1-5 and Group 7 (0\%), Group 6(3.33\%), Group 10(4.11\%), Groups 13,15 (2.74\%) and Group 17 (1.37\%) (Table 2, Figure 3).

\section{Metastatic rates of subgroups of lymph nodes}

We also analyzed the metastatic rates of several subgroups of lymph nodes based on tumor locations. The metastatic rates of subgroups of lymph nodes for patients with pancreatic head cancer were listed in Table 3 (not including paraaortic lymph nodes). For patients with pancreatic head cancer, commonly involved lymph nodal subgroups were $8 \mathrm{a}, 12 \mathrm{~b}, 13 \mathrm{a}, 13 \mathrm{~b}$, $14 \mathrm{a}, 14 \mathrm{~b}, 14 \mathrm{~d}, 17 \mathrm{a}$ and $17 \mathrm{~b}$. However, tumor rarely spread to proximal and distal splenic lymph nodes (11p, 11d), lymph nodes around the proper hepatic artery (12a) which had $<5 \%$ metastatic rates. The distribution of lymph nodal subgroups (not including paraaortic lymph nodes) for patients with pancreatic body/tail tumor was not described in any study.

In addition, the distribution of paraaortic lymph nodes based on the locations of tumors was analyzed $[17,20,26]$. Similar lymph nodal distributions for disease from pancreatic head cancer and body/tail cancer were found. Wherever the primary tumors were situated, the majority of the positive lymph nodes were located in the areas between the celiac artery and the inferior mesenteric artery (metastatic rate of pancreatic head cancer: 17.3\%; metastatic rate of pancreatic body/tail cancer: $17.4 \%$ ), while other areas including those superior to the celiac artery or inferior to the inferior mesenteric artery had $<2 \%$ in metastatic rates. In the areas between the celiac artery and the inferior mesenteric artery, the positive lymph nodes were mainly located anterior to the abdominal aorta (Area pre-aor) and the area between the abdominal aorta and the inferior vena cava (Area inter) (metastatic rate of pancreatic head cancer: Area pre-aor $8.6 \%$, Area inter $11.7 \%$; metastatic rate of pancreatic body/tail cancer: Area pre-aor 13\%, Area inter $13 \%)$, while other areas including those posterior and lateral to the aorta and the vena cava and those anterior to the vena cava had $<4 \%$ in metastatic rates.

\section{Correlation between metastasis to lymph nodes and tumor characteristics}

We analyzed the correlation between the metastatic rates of all groups of lymph nodes and tumor characteristics ( $\mathrm{T}$ stage, tumor differentiation, lymphatic vessel invasion and tumor size). There were three studies describing the distribution of lymph nodes based on tumor characteristics, 2 about pancreatic head cancer and 1 about pancreatic body/tail tumor. Two studies about pancreatic head cancer analyzed 6 groups of lymph nodes (according to JPS Classification), including lymph nodes around the celiac trunk (group 9), lymph nodes of the hepatoduodenal ligament (group 12), posterior pancreaticoduodenal lymph nodes (group 13), lymph nodes around the superior mesenteric artery (group 14), paraaortic lymph nodes (group 16), anterior pancreaticoduodenal lymph nodes (group 17). Altogether, there were only a few sites where frequency of spread was correlated with tumor characteristics, including group 12 and group 13 (these two groups correlated 
Table 2 Metastatic rates of all groups of lymph nodes (According to JPS Classification)

\begin{tabular}{|c|c|c|c|c|c|c|c|c|c|c|c|c|c|c|c|c|c|c|}
\hline $\begin{array}{l}\text { No. Group } \\
\text { No. Study }\end{array}$ & $\begin{array}{c}1 \\
\mathrm{RC}\end{array}$ & $\begin{array}{c}2 \\
L C\end{array}$ & $\begin{array}{l}3 \\
\text { LCS }\end{array}$ & $\begin{array}{c}4 \\
\text { GCS }\end{array}$ & $\begin{array}{c}5 \\
\text { SP }\end{array}$ & $\begin{array}{l}6 \\
\text { IP }\end{array}$ & $\begin{array}{c}7 \\
\text { LGA }\end{array}$ & $\begin{array}{c}8 \\
\text { CHA }\end{array}$ & $\begin{array}{c}9 \\
\text { CT }\end{array}$ & $\begin{array}{l}10 \\
\text { HS }\end{array}$ & $\begin{array}{l}11 \\
\text { SA }\end{array}$ & $\begin{array}{c}12 \\
\mathrm{HDL}\end{array}$ & $\begin{array}{c}13 \\
\text { PPD }\end{array}$ & $\begin{array}{c}14 \\
\text { SMA }\end{array}$ & $\begin{array}{c}15 \\
\text { MCA }\end{array}$ & $\begin{array}{l}16 \\
\mathrm{PA}\end{array}$ & $\begin{array}{c}17 \\
\text { APD }\end{array}$ & $\begin{array}{l}18 \\
\text { IB }\end{array}$ \\
\hline \multicolumn{19}{|c|}{$\begin{array}{c}\text { Pancreatic Head } \\
\text { Cancer }\end{array}$} \\
\hline 1 & & & & & & & & & $8 / 175$ & $2 / 175$ & & $31 / 175$ & $65 / 175$ & $17 / 175$ & & $39 / 175$ & $41 / 175$ & \\
\hline 2 & $\begin{array}{l}12 / \\
2974\end{array}$ & $\begin{array}{c}8 / \\
2768\end{array}$ & $\begin{array}{l}48 / \\
3796\end{array}$ & $\begin{array}{c}57 / \\
3928\end{array}$ & $\begin{array}{l}721 \\
3973\end{array}$ & $\begin{array}{l}298 / \\
4167\end{array}$ & $\begin{array}{c}70 / \\
3697\end{array}$ & $\begin{array}{l}728 / \\
7453\end{array}$ & $\begin{array}{l}130 / \\
3697\end{array}$ & $\begin{array}{c}23 / \\
2759\end{array}$ & $\begin{array}{l}121 / \\
8260\end{array}$ & $921 / 12400$ & $\begin{array}{l}2588 / \\
8503\end{array}$ & $\begin{array}{l}1182 / \\
7962\end{array}$ & $97 / 3364$ & $\begin{array}{l}501 / \\
5134\end{array}$ & $\begin{array}{l}1524 / \\
8148\end{array}$ & $84 / 3266$ \\
\hline $3^{*}$ & & & & & & & & $5 / 76$ & $3 / 76$ & $0 / 76$ & $1 / 76$ & $11 / 76$ & $75 / 76$ & $26 / 76$ & $0 / 76$ & $14 / 76$ & $35 / 76$ & $0 / 76$ \\
\hline 4 & $0 / 96$ & $0 / 96$ & $0 / 96$ & $0 / 96$ & $0 / 96$ & $0 / 96$ & $0 / 96$ & $12 / 96$ & $6 / 96$ & $1 / 96$ & $3 / 96$ & $14 / 96$ & & $11 / 96$ & $0 / 96$ & $10 / 96$ & & $0 / 96$ \\
\hline 5(6)\# & & & $0 / 42$ & $0 / 42$ & $0 / 42$ & $1 / 42$ & $0 / 42$ & $6 / 42$ & $2 / 42$ & $0 / 42$ & $2 / 42$ & $9 / 42$ & $29 / 42$ & $16 / 42$ & $0 / 42$ & $7 / 42$ & $17 / 42$ & $5 / 20$ \\
\hline 7 & & & & & $0 / 100$ & $12 / 100$ & & $6 / 100$ & $9 / 100$ & & & $3 / 100$ & & $22 / 100$ & $3 / 100$ & & & \\
\hline 12 & & & & & $0 / 44$ & $1 / 44$ & $0 / 44$ & $6 / 44$ & $2 / 44$ & $0 / 44$ & $2 / 44$ & $6 / 44$ & $28 / 44$ & $15 / 44$ & $0 / 44$ & $7 / 44$ & $14 / 44$ & $4 / 44$ \\
\hline 13 & & & & & & & & & & & & & & & & $9 / 34$ & & \\
\hline 14 & & & & & & $21 / 178$ & $0 / 178$ & $17 / 178$ & $2 / 178$ & $0 / 178$ & $14 / 178$ & $33 / 178$ & $83 / 178$ & $50 / 178$ & $2 / 178$ & $34 / 178$ & $51 / 178$ & $3 / 178$ \\
\hline 15 & & & $0 / 50$ & $0 / 50$ & & & & & & & & & & & & & & \\
\hline 16 & & & & & & & $2 / 81$ & $9 / 81$ & $2 / 81$ & $1 / 81$ & & $12 / 81$ & $40 / 81$ & $38 / 81$ & $5 / 81$ & $15 / 81$ & $30 / 81$ & \\
\hline 17 & & & & & & & & $6 / 49$ & $2 / 49$ & & & $6 / 49$ & $48 / 49$ & $18 / 49$ & & $9 / 49$ & $27 / 49$ & \\
\hline $\begin{array}{l}\text { Total } \\
\text { (head) }\end{array}$ & $\begin{array}{l}12 / \\
3070\end{array}$ & $\begin{array}{c}8 / \\
2864\end{array}$ & $\begin{array}{c}48 / \\
3984\end{array}$ & $\begin{array}{l}57 / \\
4116\end{array}$ & $\begin{array}{l}72 / \\
4255\end{array}$ & $\begin{array}{l}333 / \\
4627\end{array}$ & $\begin{array}{c}72 / \\
4138\end{array}$ & $\begin{array}{l}795 / \\
8119\end{array}$ & $\begin{array}{l}166 / \\
4538\end{array}$ & $\begin{array}{c}27 / \\
3451\end{array}$ & $\begin{array}{l}143 / \\
8696\end{array}$ & $\begin{array}{l}1046 / \\
13241\end{array}$ & $\begin{array}{l}2956 / \\
9148\end{array}$ & $\begin{array}{l}1395 / \\
8803\end{array}$ & $\begin{array}{l}107 / \\
3981\end{array}$ & $\begin{array}{l}645 / \\
5909\end{array}$ & $\begin{array}{l}1739 / \\
8793\end{array}$ & $96 / 3680$ \\
\hline $\begin{array}{l}{ }^{1} \text { Total rate } \\
\text { (head) \% }\end{array}$ & 0.39 & 0.28 & 1.2 & 1.38 & 1.69 & 7.2 & 1.74 & 9.79 & 3.66 & 0.78 & 1.64 & 7.9 & 32.31 & 15.85 & 2.69 & 10.92 & 19.78 & 2.61 \\
\hline \multicolumn{19}{|c|}{ Pancreatic Body/tail Cancer } \\
\hline $3^{*}$ & & & & & & & & $5 / 23$ & $1 / 23$ & $1 / 23$ & $11 / 23$ & $3 / 23$ & $1 / 23$ & $1 / 23$ & $1 / 23$ & $4 / 23$ & $0 / 23$ & $9 / 23$ \\
\hline 9 & $0 / 30$ & $0 / 30$ & $1 / 30$ & $0 / 30$ & $0 / 30$ & $1 / 30$ & $0 / 30$ & $1 / 30$ & $4 / 30$ & $1 / 30$ & $5 / 30$ & $0 / 30$ & $0 / 30$ & $4 / 30$ & $0 / 30$ & $4 / 30$ & $1 / 30$ & $2 / 30$ \\
\hline 11 & & & & & & & & $5 / 20$ & $2 / 20$ & $1 / 20$ & $10 / 20$ & $3 / 20$ & $1 / 20$ & $2 / 20$ & $1 / 20$ & $4 / 20$ & $0 / 20$ & $7 / 20$ \\
\hline $\begin{array}{c}\text { Total } \\
\text { (body/tail) }\end{array}$ & $0 / 30$ & $0 / 30$ & $0 / 30$ & $0 / 30$ & $0 / 30$ & $1 / 30$ & $0 / 30$ & $11 / 73$ & $7 / 73$ & $3 / 73$ & $26 / 73$ & $6 / 73$ & $2 / 73$ & $7 / 73$ & $2 / 73$ & $12 / 73$ & $1 / 73$ & $18 / 73$ \\
\hline $\begin{array}{l}{ }^{1} \text { Total rate } \\
\text { (Body/tail)\% }\end{array}$ & 0 & 0 & 0 & 0 & 0 & 3.33 & 0 & 15.07 & 9.59 & 4.11 & 35.62 & 8.22 & 2.74 & 9.59 & 2.74 & 16.44 & 1.37 & 24.66 \\
\hline \multicolumn{19}{|c|}{ General Pancreatic Cancer } \\
\hline 8 & & & & & & & & & & $0 / 22$ & & $0 / 22$ & $10 / 22$ & $1 / 22$ & $1 / 22$ & & $2 / 22$ & \\
\hline 10 & & & & & & & & & & $0 / 8$ & & $0 / 8$ & $4 / 8$ & & & $4 / 8$ & $2 / 8$ & \\
\hline 18 & & & & & & $1 / 10$ & & & & & & $1 / 10$ & $1 / 10$ & $1 / 10$ & & & $6 / 10$ & \\
\hline
\end{tabular}


Table 2: Metastatic rates of all groups of lymph nodes (According to JPS Classification) (Continued)

\begin{tabular}{|c|c|c|c|c|c|c|c|c|c|c|c|c|c|c|c|c|c|c|}
\hline $\begin{array}{c}\text { Total } \\
\text { (general) }\end{array}$ & & & & & & $1 / 10$ & & & & $0 / 30$ & & $1 / 40$ & $15 / 40$ & $2 / 32$ & $1 / 22$ & $4 / 8$ & $10 / 40$ & \\
\hline $\begin{array}{l}{ }^{1} \text { Total rate } \\
\text { (general)\% }\end{array}$ & & & & & & 10 & & & & 0 & & 2.5 & 37.5 & 6.25 & 4.55 & 50 & 25 & \\
\hline \multicolumn{19}{|l|}{ Total patients } \\
\hline Total & $\begin{array}{c}12 / \\
3100\end{array}$ & $\begin{array}{c}8 / \\
2894\end{array}$ & $\begin{array}{c}48 / \\
4014\end{array}$ & $\begin{array}{c}57 / \\
4146\end{array}$ & $\begin{array}{c}72 / \\
4285\end{array}$ & $\begin{array}{l}335 / \\
4667\end{array}$ & $\begin{array}{l}72 / \\
4168\end{array}$ & $\begin{array}{l}806 / \\
8192\end{array}$ & $\begin{array}{l}173 / \\
4611\end{array}$ & $\begin{array}{c}30 / \\
3554\end{array}$ & $\begin{array}{l}169 / \\
8769\end{array}$ & $\begin{array}{l}1053 / \\
13354\end{array}$ & $\begin{array}{l}2973 / \\
9261\end{array}$ & $\begin{array}{l}1404 / \\
8908\end{array}$ & $\begin{array}{l}110 / \\
4076\end{array}$ & $\begin{array}{l}661 / \\
5990\end{array}$ & $\begin{array}{l}1750 / \\
8906\end{array}$ & $\begin{array}{l}114 / \\
3753\end{array}$ \\
\hline${ }^{2}$ Total rate\% & 0.39 & 0.28 & 1.2 & 1.37 & 1.68 & 7.18 & 1.73 & 9.84 & 3.75 & 0.84 & 1.93 & 7.89 & 32.1 & 15.76 & 2.7 & 11.04 & 19.65 & 3.04 \\
\hline
\end{tabular}

Abbreviations:

Group1: right cardial lymph nodes (RC)

Group2: left cardial lymph nodes (LC)

Group3: lymph nodes along the lesser curvature of the stomach (LCS)

Group4: lymph nodes along the greater curvature of the stomach (GCS)

Group5: suprapyloric lymph nodes (SP)

Group6: infrapyloric lymph nodes (IP)

Group7: lymph nodes around the left gastric artery (LGA)

Group8: lymph nodes around the common hepatic artery (CHA)

Group9: lymph nodes around the celiac trunk (CT)

Group10: lymph nodes at the hilus of the spleen (HS)

Group11: lymph nodes along the splenic artery (SA)

Group12: lymph nodes of the hepatoduodenal ligament (HDL)

Group13: posterior pancreaticoduodenal lymph nodes (PPD)

Group14: lymph nodes around the superior mesenteric artery (SMA)

Group15: lymph nodes along the middle colic artery (MCA)

Group16: paraaortic lymph nodes (PA)

Group17: anterior pancreaticoduodenal lymph nodes (APD)

Group18: inferior body lymph nodes (IB)

${ }^{1}$ Total rate (head or body/tail or general) $=$ (patient number with positive nodes in all studies mentioning such group of lymph node)/(patient number of all studies mentioning

such group of lymph node) (for head or body/tail or general)

${ }^{2}$ Total rate $=$ (patient number with positive nodes in all studies mentioning such group of lymph node)/(patient number of all studies mentioning such group of lymph node) (for all pancreatic cancers)

*The data of Study No.3 was divided into 2 parts according to the location of the tumor.

"Study No.5 had the same patients with Study No.6. 
with lymphatic vessel invasion). One study about pancreatic body/tail cancer analyzed 8 groups of lymph nodes, including lymph nodes around the common hepatic artery (group 8), lymph nodes around the celiac trunk (group9), lymph nodes along the splenic artery (group 11), lymph nodes of the hepatoduodenal ligament (group 12), posterior pancreaticoduodenal lymph nodes (group 13), lymph nodes around the superior mesenteric artery (group 14), paraaortic lymph nodes (group 16), inferior body lymph nodes (group 18). Eventually, there was no significant correlation between distribution of lymph nodes and tumor characteristics.

\section{Discussion}

Pancreatic cancer is a highly aggressive GI malignancy. The outcome of patients with pancreatic cancer, even after complete surgical resection for early stage diseases is usually dismal, and locoregional recurrence is a major mode of treatment failure in both resected and unresectable cases. Radiation therapy is a major cancer treatment modality in both adjuvant and definitive settings; however, its use in pancreatic cancer, either definitively or adjuvantly, has been a focus of debate [33]. The suboptimal outcome after radiation therapy is due to, at least in part, insufficient dose to both gross and subclinical regions [33,34].

Irradiation to a large abdominal volume using conventional radiation to a high dose usually induces severe treatment-related side effects and complications. The advances in radiation therapy technology especially the use of IMRT have made precision targeting with high dose radiation therapy possible in the treatment of upper abdominal disease [11,12,35]. However, optimal strategy of selection and delineation of the subclinical regional disease in clinical target volume (CTV) in the treatment of pancreatic cancer has not been addressed. With more effective chemotherapy for systemic treatment of pancreatic cancer, effective local therapy to both tumor/surgical bed and the subclinical regional lymph node regions may become one of the deterministic factors for disease control in the treatment of nonmetastatic pancreatic cancer. As the subclinical involvement of lymph nodes cannot be reliably discovered by image studies including CT, MRI, and/or PET/CT [36-38], proper selection and delineation of CTV should be accounted for the major challenge for radiation oncologists in the treatment of this disease. However, no evidence-based recommendations for target volume definition especially CTV have been provided for conformal radiation therapy for pancreatic cancer.

The current study analyzed all available clinical evidence on the pattern of lymph node metastases based on pathological examination after definitive surgery, and concluded that the pattern, namely the probability and sites of lymph node metastasis from tumors originated from the head or the body/tail of the pancreas can be followed. In patients with pancreatic head cancer, the most commonly involved lymph node regions include lymph nodes around the common hepatic artery, posterior pancreaticoduodenal lymph nodes, lymph nodes around the superior mesenteric artery, paraaortic lymph nodes and anterior pancreaticoduodenal lymph nodes. These nodal regions should be considered as the highrisk regions and encompassed in CTV. Some of the above-mentioned nodal groups can be further differentiated anatomically in the context of pancreatic cancer. For lymph nodes around the superior mesenteric artery (group 14), the metastatic rate of the subgroup 14c (lymph nodes at the root of the medial colic artery) was $6.6 \%$, thus encompassing group $14 \mathrm{c}$ may not be

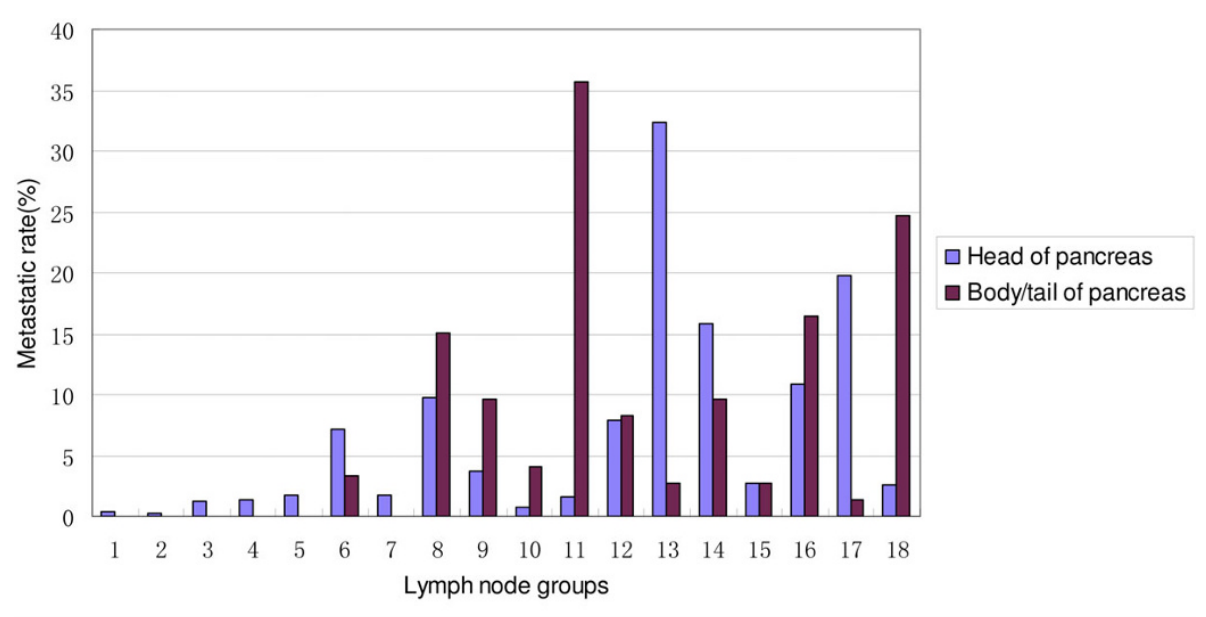

Figure 3 Frequency of lymph nodal metastasis of pancreatic cancer. 
Table 3 Metastatic rates of subgroups of lymph nodes of pancreatic head cancer (paraaortic lymph nodes not included)

\begin{tabular}{|c|c|c|c|c|c|c|c|c|c|c|c|c|c|c|c|}
\hline No. Study & $8 a$ & $8 p$ & $11 p$ & 11d & $12 a$ & $12 p$ & $12 b$ & $13 a$ & $13 b$ & $14 a$ & $14 b$ & $14 c$ & $14 d$ & $17 a$ & $17 b$ \\
\hline 3 & & & & & & & & $40 / 76$ & $35 / 76$ & $13 / 76$ & $16 / 76$ & $5 / 76$ & $9 / 76$ & $22 / 76$ & $13 / 76$ \\
\hline 6 & & & & & & & & $22 / 42$ & $19 / 42$ & $8 / 42$ & $11 / 42$ & $3 / 42$ & $6 / 42$ & $13 / 42$ & $9 / 42$ \\
\hline 2 & $523 / 3695$ & $205 / 3030$ & $121 / 3229$ & 0/4910 & 180/3887 & $257 / 3808$ & $484 / 3784$ & $1490 / 2830$ & $1098 / 3085$ & & & & & $764 / 3282$ & $760 / 3342$ \\
\hline 12 & & & & & & & & $22 / 44$ & $18 / 44$ & $8 / 44$ & $9 / 44$ & $3 / 44$ & $6 / 44$ & $11 / 44$ & $7 / 44$ \\
\hline 17 & & & & & & & & $25 / 49$ & $23 / 49$ & $10 / 49$ & $11 / 49$ & $3 / 49$ & $7 / 49$ & $16 / 49$ & $11 / 49$ \\
\hline Metastatic rate\% & 14.2 & 6.8 & 3.7 & 0 & 4.6 & 6.7 & 12.8 & 52.6 & 36.2 & 18.5 & 22.3 & 6.6 & 13.3 & 23.6 & 22.5 \\
\hline
\end{tabular}

Abbreviations:

$8 \mathrm{a}=$ lymph nodes of the anterior-superior region (group 8 )
$8 \mathrm{p}=$ lymph nodes of the posterior region (group 8 )

$11 p=$ proximal splenic lymph nodes (group 11)

$11 \mathrm{~d}=$ distal splenic lymph nodes (group 11)

$12 \mathrm{a}=$ lymph nodes around the proper hepatic artery (group 12)

$12 p=$ lymph nodes around the portal vein (group 12)

$12 \mathrm{~b}=$ lymph nodes around the bile duct (group 12)

$13 \mathrm{a}=$ lymph nodes above the papilla of Vater (group 13)

$13 \mathrm{~b}=$ lymph nodes below the papilla of Vater (group 13)

$14 \mathrm{a}=$ lymph nodes at the root of the superior mesenteric artery (group 14)

$14 \mathrm{~b}=$ lymph nodes at the root of the inferior pancreatoduodenal artery (group 14)

$14 \mathrm{c}=$ lymph nodes at the root of the medial colic artery (group 14)

$14 \mathrm{~d}=$ lymph nodes at the root of the intestinal arteries (group 14)

$17 \mathrm{a}=$ lymph nodes above the papilla of Vater (group 17)

$17 \mathrm{~b}=$ lymph nodes below the papilla of Vater (group 17) 
necessary in CTV for radiation therapy. Likewise, lymph nodes around the common hepatic artery (group 8) have a number of subgroups. The metastatic rate to group $8 \mathrm{p}$ (lymph nodes of the posterior region) was seen in $6.8 \%$ of cases. However, since such finding was seen in only one study, exclusion of group $8 p$ cannot be recommended.

The collective evidence also demonstrated that the probability of metastasis to nodal group 1-7 described by the JPS including peri-gastric and infrapyloric nodes are relatively rare (all less than 10\%). Therefore, group 1-7 can be excluded from the high-dose coverage during precision radiation therapy. The metastatic rate to the hepatoduodenal ligament (group 12) was $7.9 \%$, and could be considered as a "low-risk" region. However, once lymphatic invasion occurs, the rate of involvement raised to $20.7 \%$. In addition, hepatoduodenal ligament group is a potential lymphatic route to hepatic metastasis [16]. Therefore, it is reasonable to encompass hepatoduodenal ligament group in the CTV unless lymphatic invasion is absent in pathology examination after complete resection.

The extent of cancer including that of lymph node metastasis is usually associated to certain characteristics of the disease such as the extent of the primary disease, differentiation, and lymphatic vessel invasion, etc. However, the collective data and analyses in the current study failed to demonstrate such correlation. As most of the patients included in the 18 studies in our analyses were surgically resectable, such counterintuitive finding could only demonstrated that lymph node metastasis may occur in the earliest stage of pancreatic cancer. Such phenomenon may indicate the important of adjuvant therapy in definitive treatment of pancreatic cancer, and reduced target volume may not be ideal even for small and/or well-differentiated tumors at early stages.

The most commonly involved lymph node regions in pancreatic body/tail cancers include those around the common hepatic artery, lymph nodes around the celiac trunk, lymph nodes along the splenic artery, lymph nodes around the superior mesenteric artery, paraaortic lymph nodes and inferior body lymph nodes. Therefore, these regions should be included in the target volumes. With limited data on pancreatic body/tail cancers, no correlation between lymph node metastatic rates and tumor characteristics was observed. Therefore, no change in CTV selection and delineation is recommended according to tumor characteristics for the pancreatic body/tail cancers.

Para-aortic lymph nodes, despite its more distant location in pancreatic cancer, have relatively high probability of disease involvement, according to 14 of the 18 studies included, for both head and body/tail cancers of the pancreas [1,16-20,23-28,30,31]. Para-aortic nodes can be categorized according to their anatomic position and the probability of metastasis in pancreatic cancer. Para-aortic lymph nodes anterior to the aorta and in-between aorta and vena cava from the celiac artery to the inferior mesenteric artery had much higher metastatic rates than those lateral and posterior to the aorta and vena cava and those anterior to the vena cava (metastatic rates all $<4 \%$ ). Therefore, high radiation dose regions should encompass at least the nodes anterior and medial to the aorta between celiac and inferior mesenteric artery.

One of the recent developments in image technology that may provide more accurate selection and delineation of CTV in pancreatic cancer is the use of functional image studies. The prevailing use of functional imaging especially FDG-PET/CT may provide more accurate diagnosis of regional node diagnosis in many neoplasms. And the effectiveness of FDG-PET/CT in the selection and delineation of both primary tumor and regional metastasis has been demonstrated in a number of malignancies including lung cancer and head and neck cancers [39-41]. The sensitivity and specificity of FDG-PET/ $\mathrm{CT}$ in the diagnosis and evaluation of pancreatic cancer were reportedly $71-100 \%$ and $64-95 \%$, respectively, significantly higher than those of CT scans $[42,43]$. However, false-positive FDG-PET findings may be seen in inflammatory conditions, while hyperglycemia and small tumor sizes may results in false-negative results. In addition, most of the lymph node metastasis remains undetectable because of their small size, for which a low sensitivity range between $20 \%-35 \%$ was observed $[36,44]$. Clearly, the capability of FDG-PET/CT in detecting subclinical disease in lymph node is limited, and the use of the results of FDG-PET/CT to guide CTV-node delineation is not feasible at this time.

The pathologic findings summarized in the current analyses represent a factorial summary of the pattern of lymph node metastasis in patients with resectable pancreatic cancer. However, the clinical value, i.e., the application of such results in clinical practice is largely unknown. In resectable pancreatic cancer, the extent of treatment to the lymph node is controversial. The results of a number of retrospective studies from Japan indicated that extended lymphadenectomy were associated with improved long-term survival, and the 5-year overall survival of patients underwent extended lymphadenectomy approached 30\%-35\% [15,45]. However, such findings were not universally supported from the results of prospective randomized clinical trials published recently. Results from most trials indicated that although extended lymphadenectomy showed similar perioperative morbidity and mortality as standard lymphadenectomy, no long-term survival benefits were identified [46-48]. Two of these studies reported severe diarrhea in a high percentage of patients after extended 
lymphadenectomy $[47,48]$. Although most physicians would agree on the necessity to resect regional lymphatic areas with high metastatic rate electively $[3,17,18,20,49]$, the efficacy of radiation therapy to those areas, with or without extended lymphadenectomy, remains a focus of clinical trial. In addition, more than $85 \%$ of pancreatic cancer cases present as locally advanced and unresectable disease, and regional metastasis to lymph nodes may be more extensive than in resectable cases.

Under these circumstances, the collective data presented in the current analyses serves as a hypothesis generated for further clinical trials, preferably in prospective fashion, to investigate the efficacy of elective radiation therapy to the regional lymph nodes in adjuvant or definitive treatment using precision radiation therapy. However, such effort is further complicated by reduced accuracy of target volume contouring due to movement caused by respiration [50], and increased treatment volume to compensate such inaccuracy may cause intolerable toxicity if high-dose radiation therapy is implemented $[51,52]$. In addition, isolated recurrence in the regional lymph nodes is rare in pancreatic cancer, and the main mode of treatment failure include both local/ regional and distant metastasis. Nevertheless, improvement in outcome including systemic disease control has been observed with the use of more effective chemotherapy agent such as gemcitabine [53]. Furthermore, the concurrent use of chemotherapy and IMRT in definitive treatment of pancreatic has been reported $[54,55]$. To further evaluate the efficacy of concurrent gemcitabine and IMRT with dose escalation under active breathing control $(A B C)$ in the treatment of unresected locally advanced pancreatic cancer, a Phase II clinical trial has been initiated in the participating institutions of the current analyses. However, due to the limited number of patients who present with early stage pancreatic cancer and could achieve complete resection, investigation on the clinical value of adjuvant radiation therapy to the high-risk nodal regions in resectable pancreatic cancer will not be possible without multi-institutional effort.

\section{Conclusions}

Regional lymph node metastases in pancreatic cancer follow a predictable pattern based on the origin of the disease within pancreas. Clinical target volume of radiation therapy for subclinical disease should be designed with consideration of the probability of nodal metastasis. Although clinical investigation is needed to validate the efficacy of elective radiation therapy to the high-risk regions, the suggested strategy based on pooled analyses of clinical evidences forms a reasonable recommendation of CTV-Node definition in precision radiation therapy of resectable pancreatic cancer.

\section{Acknowledgements}

None.

\section{Author details}

'Department of Radiation Oncology, Fudan University Shanghai Cancer Center Department of Oncology, Shanghai Medical College, Fudan University, Shanghai 200032, China. ${ }^{2}$ Department of Radiation Oncology, National University Cancer Institute, National University Health System, National University of Singapore, Singapore 119074, Republic of Singapore.

\section{Authors' contributions}

WJS collected and analyzed data and performed statistical analysis. WJS and $J \mathrm{~L}$ drafted the manuscript. CNL reviewed the data and revised the manuscript. ZZ and $J \mathrm{~L}$ designed the study and revised the final version. All authors have read and approved the final version of the manuscript.

\section{Competing interests}

The authors declare that they have no competing interests.

Received: 1 February 2010 Accepted: 15 April 2010

Published: 15 April 2010

\section{References}

1. Matsuno S, Egawa S, Fukuyama S, Motoi F, Sunamura M, Isaji S, Imaizumi T, Okada S, Kato H, Suda K, Nakao A, Hiraoka T, Hosotani R, Takeda K: Pancreatic Cancer Registry in Japan: 20 years of experience. Pancreas 2004, 28:219-230.

2. Griffin JF, Smalley SR, Jewell W, Paradelo JC, Reymond RD, Hassanein RE, Evans RG: Patterns of failure after curative resection of pancreatic carcinoma. Cancer 1990, 66:56-61.

3. Sohn TA, Yeo CJ, Cameron JL, Koniaris L, Kaushal S, Abrams RA, Sauter PK, Coleman J, Hruban RH, Lillemoe KD: Resected adenocarcinoma of the pancreas-616 patients: results, outcomes, and prognostic indicators. $J$ Gastrointest Surg 2000, 4:567-579.

4. Nitecki SS, Sarr MG, Colby TV, van Heerden JA: Long-term survival after resection for ductal adenocarcinoma of the pancreas. Is it really improving? Ann Surg 1995, 221:59-66.

5. Kalser MH, Ellenberg SS: Pancreatic cancer. Adjuvant combined radiation and chemotherapy following curative resection. Arch Surg 1985, 120:899-903.

6. Klinkenbijl JH, Jeekel J, Sahmoud T, van Pel R, Couvreur ML, Veenhof $\mathrm{CH}$, Arnaud JP, Gonzalez DG, de Wit LT, Hennipman A, Wils J: Adjuvant radiotherapy and 5-fluorouracil after curative resection of cancer of the pancreas and periampullary region: phase III trial of the EORTC gastrointestinal tract cancer cooperative group. Ann Surg 1999, 230:776-782.

7. Hoffman JP, Lipsitz S, Pisansky T, Weese JL, Solin L, Benson AB: Phase II trial of preoperative radiation therapy and chemotherapy for patients with localized, resectable adenocarcinoma of the pancreas: an Eastern Cooperative Oncology group Study. J Clin Oncol 1998, 16:317-323.

8. Moertel CG, Frytak S, Hahn RG, O'Connell MJ, Reitemeier RJ, Rubin J, Schutt AJ, Weiland LH, Childs DS, Holbrook MA, Lavin PT, Livstone E, Spiro H, Knowlton A, Kalser M, Barkin J, Lessner H, Mann-Kaplan R, Ramming K, Douglas HO Jr, Thomas P, Nave H, Bateman J, Lokich J, Brooks J, Chaffey J, Corson JM, Zamcheck N, Novak JW: Therapy of locally unresectable pancreatic carcinoma: a randomized comparison of high dose (6000 rads) radiation alone, moderate dose radiation (4000 rads + 5 -fluorouracil), and high dose radiation + 5-fluorouracil: the Gastrointestinal Tumor Study Group. Cancer 1981, 48:1705-1710.

9. Gastrointestinal Tumor Study Group: Treatment of locally unresectable carcinoma of the pancreas: comparison of combined-modality therapy (chemotherapy plus radiotherapy) to chemotherapy alone. J Natl Cancer Inst 1988, 80:751-755.

10. Chmura SJ, Heimann R: Normal tissue toxicity using intensity modulated radiation therapy(IMRT) in pancreatic cancer and cholangiocarcinoma. [Abstract] Proc Am Soc Clin Oncol 2001, 20:1093.

11. Spalding AC, Jee KW, Vineberg K, Jablonowski M, Fraass BA, Pan CC, Lawrence TS, Haken RK, Ben-Josef E: Potential for dose-escalation and reduction of risk in pancreatic cancer using IMRT optimization with lexicographic ordering and gEUD-based cost functions. Med Phys 2007, 34:521-529. 
12. Brown MW, Ning H, Arora B, Albert PS, Poggi M, Camphausen K, Citrin D: A dosimetric analysis of dose escalation using two intensity-modulated radiation therapy techniques in locally advanced pancreatic carcinoma. Int J Radiat Oncol Biol Phys 2006, 65:274-283.

13. Wieland P, Dobler B, Mai S, Hermann B, Tiefenbacher U, Steil V, Wenz F, Lohr F: IMRT for postoperative treatment of gastric cancer: covering large target volumes in the upper abdomen: a comparison of a stepand-shoot and an arc therapy approach. Int I Radiat Oncol Biol Phys 2004, 59:1236-1244

14. Japan Pancreas Society: Classification of pancreatic carcinoma. Tokyo: Kanehara, 2nd English 2003.

15. Ishikawa O, Ohhigashi H, Sasaki Y, Kabuto T, Fukuda I, Furukawa H, Imaoka S, Iwanaga T: Practical usefulness of lymphatic and connective tissue clearance for the carcinoma of the pancreas head. Ann Surg 1988, 208:215-220.

16. Brunner TB, Merkel S, Grabenbauer GG, Meyer T, Baum U, Papadopoulos T, Sauer R, Hohenberger W: Definition of elective lymphatic target volume in ductal carcinoma of the pancreatic head based on histopathologic analysis. Int J Radiat Oncol Biol Phys 2005, 62:1021-1029.

17. Kayahara M, Nagakawa T, Ohta T, Kitagawa H, Ueno K, Tajima H, Elnemr A, Miwa K: Analysis of paraaortic lymph node involvement in pancreatic carcinoma: a significant indication for surgery? Cancer 1999, 85:583-590.

18. Sierzega M, Popiela T, Kulig J, Nowak K: The ratio of metastatic/resected lymph nodes is an independent prognostic factor in patients with nodepositive pancreatic head cancer. Pancreas 2006, 33:240-245.

19. Nagakawa T, Kobayashi H, Ueno K, Ohta T, Kayahara M, Mori K, Nakano T, Takeda T, Konishi I, Miyazaki I: The pattern of lymph node involvement in carcinoma of the head of the pancreas. A histologic study of the surgical findings in patients undergoing extensive nodal dissections. Int J Pancreatol 1993, 13:15-22.

20. Nagakawa T, Kobayashi H, Ueno K, Ohta T, Kayahara M, Miyazaki I: Clinical study of lymphatic flow to the paraaortic lymph nodes in carcinoma of the head of the pancreas. Cancer 1994, 73:1155-1162.

21. Capussotti L, Massucco P, Ribero D, Viganò L, Muratore A, Calgaro M: Extended lymphadenectomy and vein resection for pancreatic head cancer: outcomes and implications for therapy. Arch Surg 2003, 138:1316-1322.

22. Cubilla AL, Fortner J, Fitzgerald PJ: Lymph node involvement in carcinoma of the head of the pancreas area. Cancer 1978, 41:880-887.

23. Nakao A, Harada A, Nonami T, Kaneko T, Nomoto S, Koyama H, Kanazumi N, Nakashima N, Takagi H: Lymph node metastasis in carcinoma of the body and tail of the pancreas. Br J Surg 1997, 84:1090-1092.

24. Nagai H, Kuroda A, Morioka Y: Lymphatic and local spread of T1 and T2 pancreatic cancer. A study of autopsy material. Ann Surg 1986, 204:65-71.

25. Kayahara M, Nagakawa T, Futagami F, Kitagawa H, Ohta T, Miyazaki I: Lymphatic flow and neural plexus invasion associated with carcinoma of the body and tail of the pancreas. Cancer 1996, 78:2485-2491.

26. Kayahara M, Nagakawa T, Kobayashi H, Mori K, Nakano T, Kadoya N, Ohta T, Ueno K, Miyazaki I: Lymphatic flow in carcinoma of the head of the pancreas. Cancer 1992, 70:2061-2066.

27. Yoshida T, Matsumoto T, Sasaki A, Shibata K, Aramaki M, Kitano S: Outcome of paraaortic node-positive pancreatic head and bile duct adenocarcinoma. Am J Surg 2004, 187:736-740.

28. Sakai M, Nakao A, Kaneko T, Takeda S, Inoue S, Kodera Y, Nomoto S, Kanazumi N, Sugimoto H: Para-aortic lymph node metastasis in carcinoma of the head of the pancreas. Surgery 2005, 137:606-611.

29. Gerdes B, Ramaswamy A, Bartsch DK, Rothmund M: Peripyloric lymph node metastasis is a rare condition in carcinoma of the pancreatic head. Pancreas 2005, 31:88-92.

30. Ishikawa O, Ohigashi H, Sasaki Y, Kabuto T, Furukawa H, Nakamori S, Imaoka S, Iwanaga T, Kasugai T: Practical grouping of positive lymph nodes in pancreatic head cancer treated by an extended pancreatectomy. Surgery 1997, 121:244-249.

31. Kayahara M, Nagakawa T, Ueno K, Ohta T, Tsukioka Y, Miyazaki I: Surgical strategy for carcinoma of the pancreas head area based on clinicopathologic analysis of nodal involvement and plexus invasion. Surgery 1995, 117:616-623.

32. Kocher HM, Sohail M, Benjamin IS, Patel AG: Technical limitations of lymph node mapping in pancreatic cancer. Eur J Surg Oncol 2007, 33:887-891.

33. Hazard $\mathrm{L}$ : The role of radiation therapy in pancreas cancer. Gastrointest Cancer Res 2009, 3:20-28.
34. Withers HR, Peters $L$, Taylor JM: Dose-response relationship for radiation therapy of subclinical disease. Int I Radiat Oncol Biol Phys 1995, 31:353-359.

35. Willett CG, Clark JW: Update on combined-modality treatment options for pancreatic cancer. Oncology 2003, 17:29-36.

36. Lemke AJ, Niehues SM, Hosten N, Amthauer H, Boehmig M, Stroszczynski C, Rohlfing T, Rosewicz S, Felix R: Retrospective digital image fusion of multidetector CT and 18F-FDG PET: clinical value in pancreatic lesions-a prospective study with 104 patients. J Nucl Med 2004, 45:1279-1286.

37. De Gaetano AM, Vecchioli A, Minordi LM, Parrella A, Gaudino S, Masselli G, Savino G: Role of diagnostic imaging in abdominal lymphadenopathy. Rays 2000, 25:463-484.

38. Hanbidge AE: Cancer of the pancreas: the best image for early detection-CT, MRI, PET or US? Can J Gastroenterol 2002, 16:101-105.

39. Yu H, Caldwell C, Mah K, Poon I, Balogh J, Mackenzie R, Khaouam N, Tirona R: Automated radiation targeting in head-and-neck cancer using region-based texture analysis of PET and CT images. Int J Radiat Oncol Biol Phys 2009, 75:618-625.

40. Geets X, Lee JA, Castadot P, Bol A, Grégoire V: Potential place of FDG-PET for the GTV delineation in head and neck and lung cancers. Cancer Radiother 2009, 13:594-599.

41. Yu J, Li X, Xing L, Mu D, Fu Z, Sun X, Sun X, Yang G, Zhang B, Sun X, Ling CC: Comparison of tumor volumes as determined by pathologic examination and FDG-PET/CT images of non-small-cell lung cancer: a pilot study. Int I Radiat Oncol Biol Phys 2009, 75:1468-1474.

42. Strobel K, Heinrich S, Bhure U, Soyka J, Veit-Haibach P, Pestalozzi BC, Clavien PA, Hany TF: Contrast-enhanced 18F-FDG PET/CT: 1-stop-shop imaging for assessing the resectability of pancreatic cancer. J NuCl Med 2008, 49:1408-1413.

43. Sendler A, Avril N, Helmberger H, Stollfuss J, Weber W, Bengel F, Schwaiger M, Roder JD, Siewert JR: Preoperative evaluation of pancreatic masses with positron emission tomography using $18 \mathrm{~F}-$ fluorodeoxyglucose: diagnostic limitations. World J Surg 2000, 24:1121-1129.

44. Kitajima K, Murakami K, Yamasaki E, Kaji Y, Shimoda M, Kubota K, Suganuma N, Sugimura K: Performance of Integrated FDG-PET/Contrastenhanced $C T$ in the Diagnosis of Recurrent Pancreatic Cancer: Comparison with Integrated FDG-PET/Non-contrast-enhanced CT and Enhanced CT. Mol Imaging Biol 2009.

45. Manabe T, Ohshio G, Baba N, Miyashita T, Asano N, Tamura K, Yamaki K, Nonaka A, Tobe T: Radical pancreatectomy for ductal cell carcinoma of the head of the pancreas. Cancer 1989, 64:1132-1137.

46. Pedrazzoli S, DiCarlo V, Dionigi R, Mosca F, Pederzoli P, Pasquali C, Klöppel G, Dhaene K, Michelassi F: Standard versus extended lymphadenectomy associated with pancreatoduodenectomy in the surgical treatment of adenocarcinoma of the head of the pancreas. Ann Surg 1998, 228:508-517.

47. Yeo CJ, Cameron JL, Sohn TA, Coleman J, Sauter PK, Hruban RH, Pitt HA, Lillemoe KD: Pancreaticoduodenectomy with or without extended retroperitoneal lymphadenectomy for periampullary adenocarcinoma. Comparison of morbidity and mortality and short-term outcome. Ann Surg 1999, 229:613-624.

48. Farnell MB, Pearson RK, Sarr MG, DiMagno EP, Burgart LJ, Dahl TR, Foster N, Sargent DJ: Pancreas Cancer Working Group: A prospective randomized trial comparing standard pancreatoduodenectomy with pancreatoduodenectomy with extended lymphadenectomy in resectable pancreatic head adenocarcinoma. Surgery 2005, 138:618-630.

49. Yoshida T, Matsumoto T, Sasaki A, Shibata K, Aramaki M, Kitano S: Outcome of paraaortic node-positive pancreatic head and bile duct adenocarcinoma. Am J Surg 2004, 187:736-740.

50. Bussels B, Goethals L, Feron M, Bielen D, Dymarkowski S, Suetens P, Haustermans K: Respiration-induced movement of the upper abdominal organs: A pitfall for the three-dimensional conformal radiation treatment of pancreatic cancer. Radiother Oncol 2003, 68:69-74.

51. Crane CH, Wolff RA, Abbruzzese JL, Evans DB, Milas L, Mason K, Charnsangavej C, Pisters PW, Lee JE, Lenzi R, Lahoti S, Vauthey JN, Janjan NA: Combining gemcitabine with radiation in pancreatic cancer: Understanding important variables influencing the therapeutic index. Semin Oncol 2001, 28(3 Suppl 10):25-33.

52. Brunner TB, Grabenbauer GG, Klein P, Baum U, Papadopoulos T, Bautz W, Hohenberger W, Sauer R: Phase I trial of strictly time-scheduled 
gemcitabine and cisplatin with concurrent radiotherapy in patients with locally advanced pancreatic cancer. Int I Radiat Oncol Biol Phys 2003,

55:144-153.

53. Burris HA, Moore MJ, Andersen J, Green MR, Rothenberg ML, Modiano MR, Cripps MC, Portenoy RK, Storniolo AM, Tarassoff P, Nelson R, Dorr FA, Stephens CD, Von Hoff DD: Improvements in survival and clinical benefit with gemcitabine as first-line therapy for patients with advanced pancreas cancer: a randomized trial. J Clin Oncol 1997, 15:2403-2413.

54. Bai YR, Wu GH, Guo WJ, Wu XD, Yao Y, Chen Y, Zhou RH, Lu DQ: Intensity modulated radiation therapy and chemotherapy for locally advanced pancreatic cancer: results of feasibility study. World I Gastroenterol 2003, 9:2561-2564

55. Ben-Josef E, Shields AF, Vaishampayan U, Vaitkevicius V, El-Rayes BF, McDermott P, Burmeister J, Bossenberger T, Philip PA: Intensity-modulated radiotherapy (IMRT) and concurrent capecitabine for pancreatic cancer. Int J Radiat Oncol Biol Phys 2004, 59:454-459.

doi:10.1186/1748-717X-5-28

Cite this article as: Sun et al: Proposing the lymphatic target volume

for elective radiation therapy for pancreatic cancer: a pooled analysis of clinical evidence. Radiation Oncology 2010 5:28.

\section{Submit your next manuscript to BioMed Central and take full advantage of:}

- Convenient online submission

- Thorough peer review

- No space constraints or color figure charges

- Immediate publication on acceptance

- Inclusion in PubMed, CAS, Scopus and Google Scholar

- Research which is freely available for redistribution

Submit your manuscript at www.biomedcentral.com/submit 